\title{
Regulation of the Neurospora circadian clock by an RNA helicase
}

\author{
Ping Cheng, Qun He, Qiyang He, Lixin Wang, and Yi Liu ${ }^{1}$ \\ Department of Physiology, University of Texas Southwestern Medical Center, Dallas, Texas 75390, USA
}

\begin{abstract}
The eukaryotic circadian oscillators consist of autoregulatory negative-feedback loops. FRQ, WC-1, and WC-2 are three known components of the negative-feedback loop of the Neurospora circadian oscillator. FRQ represses its own transcription by interacting with the WC-1/WC-2 complex and inhibiting WC's role in transcriptional activation. Here we show that all FRQ associates with FRH, an essential DEAD box-containing RNA helicase in Neurospora. The budding yeast homolog of FRH, Dob1p/Mtr4p, is a cofactor of exosome, an important regulator of RNA metabolism in eukaryotes. Down-regulation of FRH by inducible expression of a hairpin RNA leads to low levels of FRQ but high levels of frq RNA and the abolishment of circadian rhythmicities. FRH is associated with the WC complex and this interaction is maintained in a frq null strain. Disruption of the FRQ-FRH complex by deleting a domain in FRQ eliminates the FRQ-WC interaction, suggesting that FRH mediates the interaction between FRQ and the WC complex. These data demonstrate that FRH is an essential component in the circadian negative-feedback loop and reveal an unexpected role of an RNA helicase in regulating gene transcription.
\end{abstract}

[Keywords: Frequency; FRH; Mtr4p; exosome; white collar-1; RNAi]

Received September 28, 2004; revised version accepted November 5, 2004.

Endogenous circadian (daily) clocks control a wide variety of physiological and molecular activities in most eukaryotic and some prokaryotic organisms. At the molecular level, autoregulatory negative-feedback loops composed of positive and negative elements form the core circadian oscillators (Dunlap 1999; King and Takahashi 2000; Reppert and Weaver 2001; Young and Kay 2001). The rhythmic activation of transcription of the negative elements by the positive elements is thought to be the main basis for the generation of the endogenous rhythmicity.

In the Neurospora frequency $\left(f_{r q}\right)$-white collar $(w c)$ based circadian negative-feedback loop, a heterodimeric complex formed by WC-1 and WC-2 (two PAS domaincontaining transcription factors) acts as the positive element and activates the transcription of $f_{r} q$ by binding to its promoter (Crosthwaite et al. 1997; Cheng et al. 2001b; Loros and Dunlap 2001; Froehlich et al. 2003). FRQ proteins (large FRQ [1FRQ] and small FRQ [sFRQ] resulting from alternative translation initiation) form homodimeric complexes and function as the negative elements in the loop by repressing their own transcription (Aronson et al. 1994a; Garceau et al. 1997; Liu et al. 1997; Cheng et al. 2001a). To close the negative-feedback loop, FRQ forms a complex with the WC proteins and pre-

${ }^{1}$ Corresponding author.

E-MAIL Yi.Liu@UTsouthwestern.edu; FAX (214) 648-7891.

Article published online ahead of print. Article and publication date are at http://www.genesdev.org/cgi/doi/10.1101/gad.1266805. vents WC from binding to the $f r q$ promoter and activating frq transcription (Cheng et al. 2001a; Denault et al. 2001; Merrow et al. 2001; Froehlich et al. 2003). In strains lacking a functional FRQ protein, the negativefeedback loop is impaired, resulting in high frq mRNA levels (Aronson et al. 1994a; Merrow et al. 1997; Yang et al. 2002). How FRQ inhibits the activity of WC complex is unclear. In frq null strains, in addition to their loss of circadian rhythmicities, less conidia and aerial hyphae are produced than a wild-type strain (Aronson et al. 1994b), suggesting that FRQ has functions outside the circadian feedback loops. In this study, we show that all FRQ proteins are in complex with FRH, a conserved RNA helicase. We demonstrate that FRH is an essential clock component in the Neurospora circadian negativefeedback loop.

\section{Results}

\section{All FRQ proteins are associated with FRH, an RNA helicase}

To understand how FRQ functions in the Neurospora circadian clock, we purified FRQ from a frq null strain that carries a c-Myc epitope-tagged FRQ construct ( $f \mathrm{rq}^{-}$, Myc-FRQ) (Cheng et al. 2001a) using a combination of anion exchange chromatography and immunoprecipitation. The Myc-tagged FRQ can rescue the circadian conidiation rhythm of the frq null strain, indicating that it functions like the wild-type FRQ. Purification using the protein extracts from a wild-type strain (lacking the My- 
c-FRQ| was used as the control. Figure 1A shows a silver-stained SDS-PAGE gel of the anti-Myc immunoprecipitates. Three specific bands were present in the Myc-FRQ sample (indicated by the large arrows). Mass spectrometric analysis of the excised bands revealed that the top band is Myc-FRQ and the $40-\mathrm{kDa}$ minor band is CK-1a. The latter was previously shown to bind FRQ in vivo and can phosphorylate FRQ in vitro (Gorl et al. 2001). The protein at $130 \mathrm{kDa}$ is a Neurospora hypothetical protein (NCU03363.1) that exhibits strong sequence similarity to eukaryotic ATP-dependent RNA helicases (Fig. 1B). Because it forms a complex with FRQ, it is named FRH (FRQ-interacting RNA helicase). There were no significant amounts of WC-1 and WC-2 found in the purification products (by Western blot and mass spectrometric analyses), suggesting that most of the FRQ/FRH complex is not associated with the WC proteins.

To confirm the FRQ-FRH interaction, FRH was immunoprecipitated from wild-type cell extract using an FRH-specific antibody. As shown in Figure 2A, FRH interacts strongly with FRQ, suggesting that they form a complex in vivo. To determine whether both proteins are in complex with each other quantitatively, immunodepletion experiments were performed using cultures grown in constant light (LL, when FRQ level is high) (Fig. 2B). Immunodepletion of FRH in the Neurospora cell extracts also led to complete depletion of FRQ, indicating that the entire pool of FRQ forms a complex with FRH. Based on the relative amounts of FRQ and FRH shown in Figure $1 \mathrm{~A}$ and the fact that FRQ selfassociates (Cheng et al. 2001a), we estimate that one FRH molecule binds to two FRQ molecules. Immuodepletion of FRQ in the cell extracts only resulted in

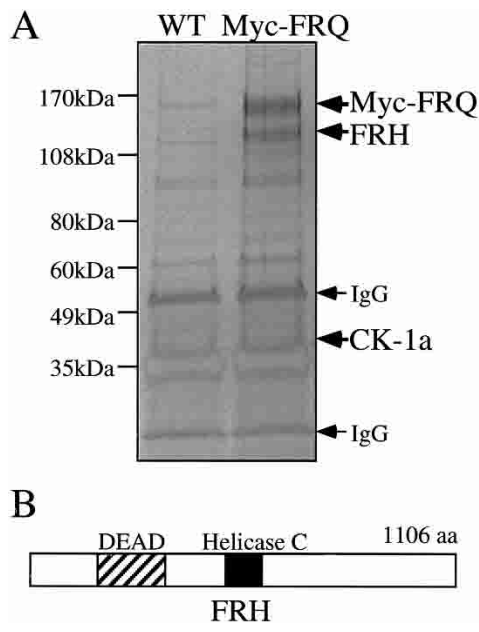

Figure 1. Identification of FRH as a FRQ-interacting protein. (A) Silver-stained SDS-PAGE gel showing the affinity purified FRQ-FRH complex. Cell extracts (prepared from LL cultures) of the wild-type and $f r q^{10}$, Myc-FRQ strains were used for purification (described in the Materials and Methods). The Myc-FRQcontaining fractions from a Q-Sepharose column purification were pooled together and immunoprecipitated with the c-Myc monoclonal antibody-coupled agarose beads. $(B)$ The domain structure of the FRH protein.

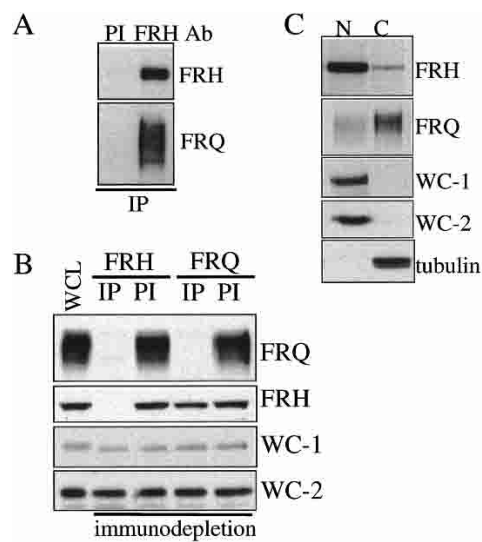

Figure 2. All FRQ proteins are in complex with FRH. $(A)$ Immunoprecipitation (IP) assay using the FRH antiserum or the preimmune serum (PI). Extracts of a wild-type strain grown in LL were used. $(B)$ Immunodepletion assay showing that all FRQ proteins are in complex with FRH. IP indicates the antiserum indicated above was used in the assay; PI indicates the preimmune serum was used. (WCL) Whole-cell lysate. (C) Nuclear and cytoplasmic distribution of FRH, FRQ, and WC proteins. (N) Nuclear fraction; (C) cytoplasmic fraction. $\alpha$-tublin was used as a cytoplasmic control. Equal amounts of nuclear or cytoplasmic proteins were loaded.

$\sim 40 \%$ reduction of the FRH level, suggesting that $\sim 40 \%$ of cellular pool of the FRH protein is in complex with FRQ. Immunodepletion using the preimmune antisera, however, did not change the levels of FRH and FRQ in the extracts, indicating the specificity of our FRH and FRQ antisera. In addition, depletion of FRH or FRQ did not significantly alter the levels of WC-1 and WC-2 in the extracts. This data is consistent with our previous purification results of the WC complex from Neurospora (He et al. 2002), indicating that most of the WC proteins are not associated with FRQ and FRH.

The putative open reading frame of FRH encodes a protein of 1106 amino acids with a predicted molecular weight of $124 \mathrm{kDa}$, consistent with its mobility on SDSPAGE. It contains a DEAD/DEAH box (ATP binding and hydrolysis) and a helicase $\mathrm{C}$ domain (Fig. 1B), both of which are found in members of the $\mathrm{DExD} / \mathrm{H}$ family of RNA helicases (Rocak and Linder 2004). Comparison of FRH with other eukaryotic RNA helicases revealed that it belongs to the SKI2 subfamily of RNA helicases (according to the classification in yeast) (Rocak and Linder 2004), and it has sequence homologs in fungi, plants, insects, and mammals. The homolog of FRH in Saccharomyces cerevisiae is the nuclear protein Doblp /also called Mtr4p) with $56 \%$ identity and $73 \%$ similarity across the entire open reading frame (Liang et al. 1996; de la Cruz et al. 1998). Doblp or its cytoplasmic counterpart, Ski2p, has been shown to be an essential nuclear (Dob1p) or cytoplasmic (Ski2p) cofactor for the yeast exosome complex. The exosome is a large complex consisting of several $3^{\prime} \rightarrow 5^{\prime}$ exonucleases and is an important regulator of RNA metabolism in eukaryotes, It is involved in $3^{\prime}$-to-5' RNA (rRNA and mRNA) processing 
and degradation (de la Cruz et al. 1998; Jacobs et al. 1998; Allmang et al. 1999; Mitchell and Tollervey 2000; Torchet et al. 2002; Hilleren and Parker 2003).

Dob1p/Mtr4p was only found in the nucleus in S. cerevisiae (Liang et al. 1996; de la Cruz et al. 1998). As shown in Figure 2C, FRH is enriched in the nuclear fraction, but it is also present in the cytoplasmic fraction. Most WC-1 and WC-2 were seen in the nuclear fraction (Schwerdtfeger and Linden 2000). Similar to earlier results (Luo et al. 1998; Cheng et al. 2001a; Yang et al. 2002), although FRQ was found in both nuclei and cytoplasm, most of FRQ was in the cytoplasm. Based on the protein yields of our fractionation experiments, we estimate that $>90 \%$ of Neurospora soluble proteins are cytoplasmic. Thus, although the concentration of the cytoplasmic FRH is low, it contributes $40 \%-50 \%$ of the total cellular pool of FRH, consistent with the result of the immunodepletion experiment. These data, combined with the immunodepletion data shown in Figure $2 \mathrm{~B}$, the different ion-exchange column elution profiles of FRQ and the WC proteins (data not shown), and our data on FRQ/FRH (Fig. 1A) and WC purifications (He et al. 2002), indicate that the majority of FRQ-FRH complexes are not associated with the WC proteins.

\section{Down-regulation of FRH leads to low FRQ levels and arrhythmicity of the clock}

Because FRQ forms a complex with FRH, we then tested whether FRH regulates FRQ in Neurospora cells in vivo. The DOB1/MTR4 gene is an essential gene in S. cerevisiae (Liang et al. 1996; de la Cruz et al. 1998). Even though we were able to create heterokaryon frh knockout strains, we were unable to obtain any homokaryon Neurospora strains in which the frh gene is disrupted by gene replacement, indicating that $f r h$ is also an essential gene in Neurospora. To study the functions of essential genes in Neurospora, we developed a method to knock down gene expression by inducibly expressing a hairpin RNA against the gene of interest (Fig. 3A; Kalidas and Smith 2002). After the induction of the hairpin doublestranded RNA (dsRNA, $\sim 500 \mathrm{bp}$ ) by an inducer, the dsRNA will be digested by the dicer enzyme in the cell to produce small interference RNA (siRNA) that triggers RNA interference (RNAi) to specifically degrade the endogenous mRNA for the gene of interest. Previously, we have successfully used this gene silencing approach to knock down gene expression of albino-3 and $f r q$ genes (P. Cheng and Y. Liu, unpubl.). To down-regulate frh, a hairpin construct specific for frh under the control of the qa-2 promoter (quinic acid inducible) (Giles et al. 1985) was transformed into a wild-type strain at the his-3 locus to create the dsfrh strain (described in Materials and Methods). Western and Northern blot analyses were then performed for cultures grown in the presence or absence of the quinic acid (QA) inducer (Fig. 3B,C). As shown in Figure 3B, in the absence of QA, the levels of FRQ and FRH in this strain were similar to those in a wild-type strain. The addition of QA, however, led to $>90 \%$ reduction of frh protein and mRNA levels (Fig.
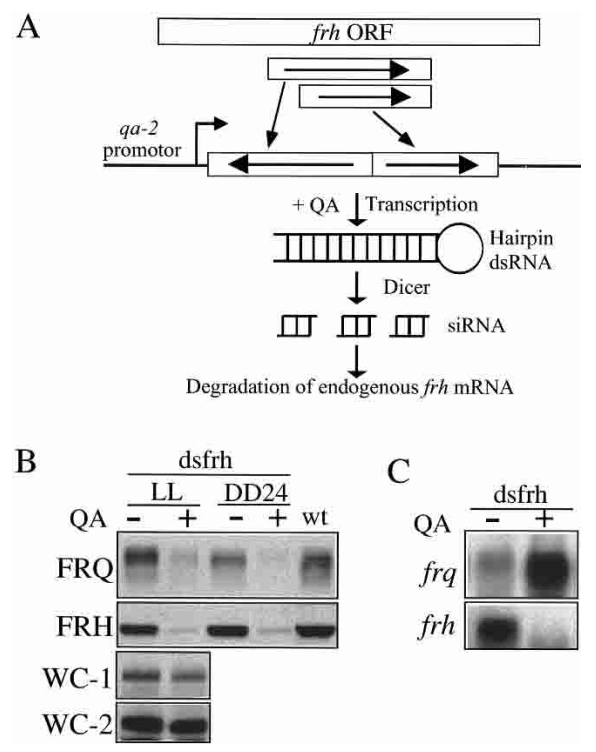

Figure 3. Down-regulation of FRH results in low levels of FRQ protein and an increase of $r q$ RNA level. $(A)$ A schematic diagram showing the inducible gene-silencing approach by expressing a hairpin RNA. $(B)$ Western blot analyses showing the expression of FRQ, FRH, and WC proteins. Cultures were harvested in LL or at DD24 (24 h in DD). The dsfrh strain was used. When QA was used, $1 \times 10^{-2} \mathrm{M}$ of QA was added to the liquid medium. $(C)$ Northern blot analyses showing the expression of frq mRNA for cultures harvested at DD24.

3B,C). The down-regulation of FRH also led to a dramatic reduction of the levels of FRQ proteins (FRQ amounts were reduced by $\sim 80 \%$ ), suggesting that $\mathrm{FRH}$ is important for maintaining the steady-state levels of FRQ, possibly by stabilizing FRQ through direct association. In contrast to the dramatic decrease of FRQ protein, the fr $q$ mRNA level was significantly elevated in the presence of QA (Fig. 3C). The high level of frq RNA suggests that the circadian negative-feedback loop is impaired when FRH is down-regulated (Aronson et al. 1994a; Yang et al. 2002). The levels of WC-1 and WC- 2 were also each reduced $\sim 30 \%$ in the presence of QA (Fig. 3B), suggesting that the positive feedback loops were also affected due to the decrease of FRQ levels (Lee et al. 2000; Cheng et al. 2001b). The reductions of FRQ and WC proteins after the down-regulation of FRH were specific, since the levels of many other proteins that cross-reacted with our antisera did not change with the addition of QA (data not shown). Previous studies have shown that the addition of QA has no effect on FRQ expression and clock function in a wild-type strain (Aronson et al. 1994a; Cheng et al. 2001b; data not shown). Because of the inducible nature of this dsRNA-mediated gene silencing approach, it should be a simple and efficient method to study gene functions, especially for essential genes, in Neurospora.

To examine whether FRH plays a role in the generation of circadian rhythmicity, circadian conidiation rhythms of the dsfrh strain were monitored using race tube assay in the presence of various concentrations of QA (Fig. 4A). It has been previously shown that the pres- 
A

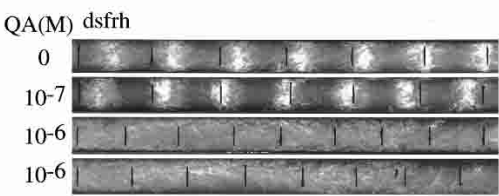

$\mathrm{B}_{\mathrm{H}}$

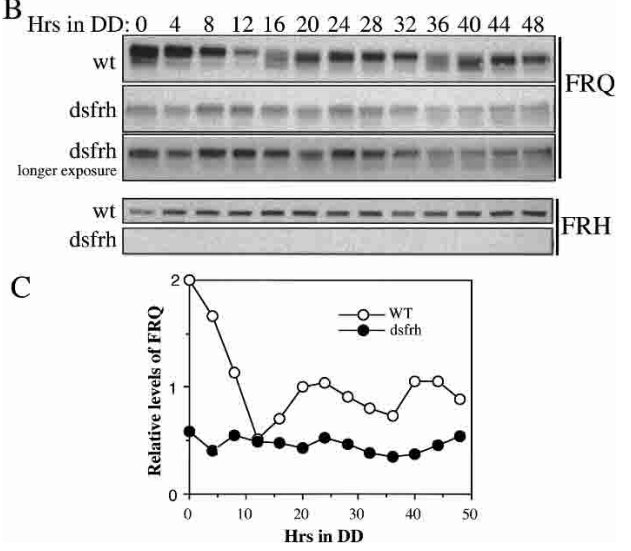

Figure 4. Down-regulation of FRH results in the loss of circadian conidiation rhythm and FRQ protein rhythms in constant darkness. (A) Race tube assays showing the conidiation rhythms of the dsfrh strain in DD on race tubes containing different concentrations of QA. Black lines indicate the growth fronts every $24 \mathrm{~h}$. (B) Western blot analyses showing the expression of FRQ and FRH in DD in the wild-type strain or the dsfrh strain. Cultures were harvested at the indicated hours in DD. QA was present in the medium for both strains. $(C)$ Densitometric analysis of FRQ Western blot result shown in $B$.

ence of QA (up to $1 \times 10^{-2} \mathrm{M}$ ) does not significantly affect the circadian conidiation rhythms of a wild-type strain in constant darkness (DD) (Aronson et al. 1994a; Cheng et al. 2001b). In race tubes without QA or containing $1 \times 10^{-7} \mathrm{M}$ QA, the dsfrh strain exhibited robust conidiation rhythms similar to those of a wild-type strain (data not shown). When QA concentration was increased to $1 \times 10^{-6} \mathrm{M}$ QA, however, conidiation became arrhythmic, suggesting that the clock was not functional. The growth rate of the strain was only slightly slower $(15 \%-20 \%)$ than that of the wild-type at this concentration of QA, suggesting the loss of the clock function is not due to the severe growth and developmental phenotypes. When higher QA concentrations were used, further reduction of the growth rate was seen and no apparent circadian conidiation rhythms were observed (data not shown), consistent with frh being an essential gene in Neurospora. These data indicate that partial reduction of FRH leads to arrhythmicity of the conidiation rhythm and that the role of FRH in regulating the clock is separated from its essential cellular functions.

At the molecular level, FRQ protein levels and their phosphorylation states exhibit robust oscillations in constant darkness in a wild-type strain (Fig. 4B; Garceau et al. 1997). In contrast, the down-regulation of frh abolished the oscillations of FRQ levels and FRQ phosphorylation states in DD and resulted in constant low levels of
FRQ in its extensive phosphorylated forms (Fig. 4B,C). The levels of FRH appear to be constant in DD in the wild-type strain, suggesting that its expression is not clock controlled. The loss of FRQ oscillation suggests that the clock is not functioning at the molecular level when the FRH level is low.

We then examined the oscillation of $f r q$ mRNA in DD after the down-regulation of frh by Northern blot analysis. In contrast to the low levels of FRQ seen in Figure 4B, frq mRNA levels remained elevated and were not rhythmic in DD in the dsfrh strain (Fig. 5A). In addition, the circadian rhythm of clock-controlled gene 2 (ccg-2) (Bell-Pedersen et al. 1992) was also abolished in the mutant strain (Fig. 5A). The high levels of frq after the down-regulation of frh are reminiscent of the high frq levels observed in a $f r q^{9}$ strain (a strain making a truncated FRQ and lacking a functional circadian negativefeedback loop) (Aronson et al. 1994a; Merrow et al. 1997). To examine whether the high levels of frq after the down-regulation of $f r h$ in a wild-type strain is mostly due to the lack of a functional negative-feedback loop, the dsfrh construct was introduced into a $f r q^{9}$ strain ( $f_{r} q^{9}$,dsfrh) and its $f_{r} q$ levels were examined in the presence or absence of QA after a light-to-dark transition. If the effect of the down-regulation of frh on frq mRNA is independent of the existence of a circadian negativefeedback loop, we expect that the down-regulation of $f r h$ in the $f r q^{9}$ strain would dramatically increase $f_{r} q$ mRNA levels similar to the data shown in Figure 5A. As shown in Figure $5 \mathrm{~B}$, the down-regulation of frh by the addition of QA in the $f r q^{9}$,dsfrh strain only resulted in a small increase of $f_{r q}$ levels, suggesting that the high frq levels

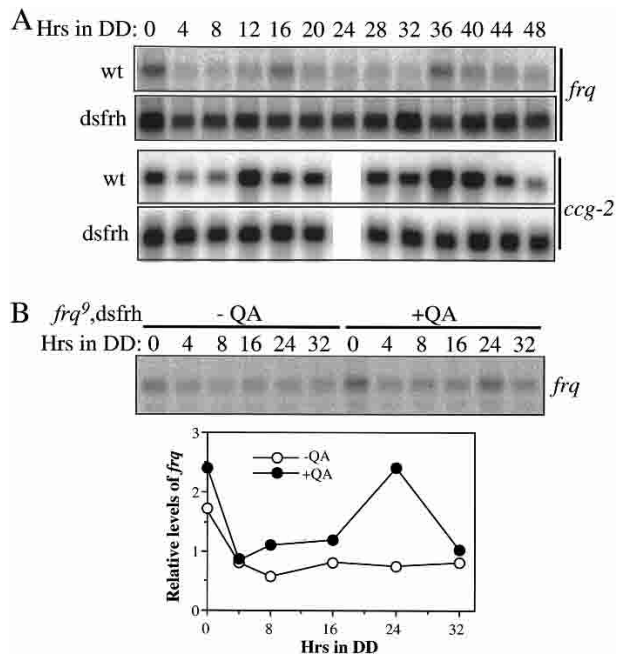

Figure 5. (A) Northern blot analyses showing the expression of frq and $c c g-2$ in DD. Cultures were harvested at the indicated hours in DD. QA was present in the medium for both strains. The RNA samples at DD24 for ccg-2 were mishandled. (B) Northern blot analyses showing the expression of $f r q$ in the fr $q^{9}$, dsfrh strain in the presence or absence of QA. Densitometric analysis of the Northern blot result is shown at the bottom. The cultures were grown for $2 \mathrm{~d}$ with or without QA in LL before they were transferred into DD. 
after the down-regulation of $f r h$ in a wild-type strain is mostly due to the lack of a functional negative-feedback loop. Together, these physiological and molecular data demonstrate that FRH is an essential clock component in the Neurospora circadian clock. Moreover, downregulation of FRH impairs the fr $-w c$ based circadian negative-feedback loop.

\section{FRH mediates the interaction between FRQ and the WC proteins}

Since FRQ interacts with the WC complex to inhibit $f r q$ transcription and to close the circadian negative-feedback loop (Aronson et al. 1994b; Cheng et al. 2001a; Denault et al. 2001; Froehlich et al. 2003), the high frq levels after the down-regulation of frh suggest that FRH may mediate the closing of the negative-feedback loop. If so, FRH should be present in the FRQ-WC complex. Indeed, an immunoprecipitation assay using our WC-2 (or WC-1) antiserum showed that, like FRQ, FRH was associated with WC-1 and WC-2 (Fig. 6A; data not shown). We then checked whether the FRH-FRQ complex is maintained in the wc mutants. Because FRQ expressed at very low levels in wC mutants (Crosthwaite et al. 1997), we used strains (wc- $1^{R I P}$, qaFRQ and $w c-2^{K O}$, qaFRQ) in which FRQ expression is controlled by a QA-inducible promoter (Cheng et al. 2002, 2003). As seen in Figure 6B, FRQ still forms a complex with FRH in these strains, indicating that the FRQ-FRH interaction is independent of the WC complex.

To examine whether the interaction between FRH and the WC complex requires FRQ, the FRH-WC interaction
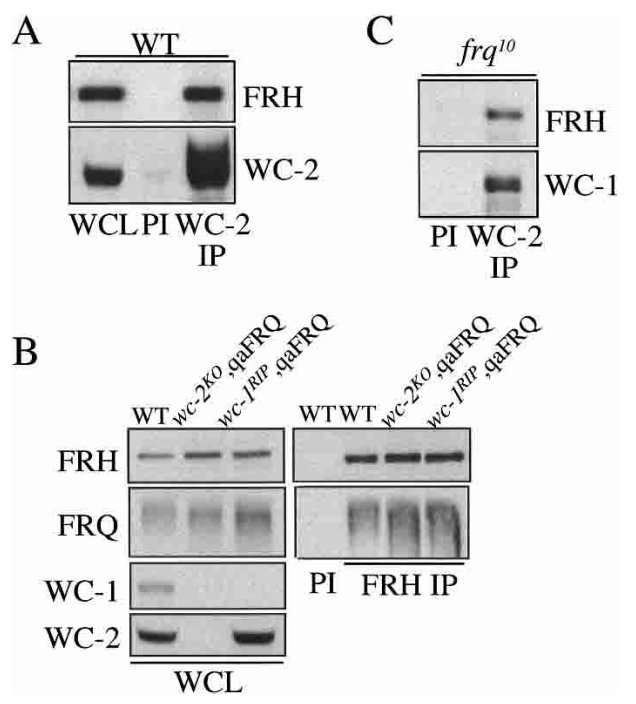

Figure 6. FRH interact with the WC complex independent of FRQ. Cultures were harvested in LL. $(A, C)$ Immunoprecipitation assay showing that FRH is associated with the WC complex in a wild-type strain $(A)$ and in a $f r q$ null $\left(f r q^{10}\right)$ strain $(C)$. The IP assays were performed using the WC- 2 antiserum (IP) or the preimmune serum (PI). (WCL) Whole cell lysate. (B) IP assay showing the FRQ-FRH interaction in $w c-1$ or $w c-2$ mutants expressing QA-inducible FRQ. FRH antiserum was used for IP.

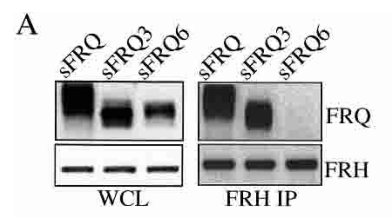

B

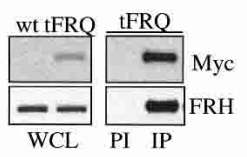

C

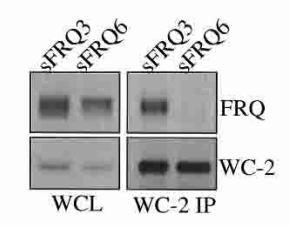

$\mathrm{D}$

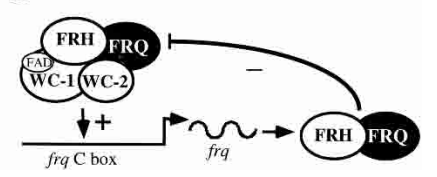

Figure 7. The interaction between FRQ and FRH is necessary for the complex formation between FRQ and the WC proteins. (A) IP assay showing the loss of FRQ-FRH interaction in the sFRQ6 mutant ( $f r q^{10}$, sFRQ6). In the sFRQ3 strain ( $r q^{10}, \mathrm{sFRQ3)}$, FRQ amino acids 328-422 were deleted from the sFRQ ORF and its FRQ level is comparable to that of sFRQ6. (B) IP assay showing that, in the tFRQ strain, the c-Myc-tagged truncated FRQ protein (FRQ amino acids 656-910) can form a complex with FRH. (C) IP assay showing the loss of FRQ-WC interactions in the sFRQ6 mutant. (D) An updated model of the Neurospora frq-wc-based circadian negative-feedback loop.

was examined in a $f r q^{10}$ strain (a $f r q$ knockout strain) (Aronson et al. 1994b). As shown in Figure 6C, FRH was coprecipitated with the WC complex. Thus, the interaction between the FRH and WC complex can occur independently of FRQ. These data, and the fact that most of FRQ is not associated with the WC complex, suggest that FRH may mediate the interaction between FRQ and the WC complex.

To further investigate this possibility, we mapped the FRQ-FRH interaction domain on FRQ using a series of mutants containing various internal in-frame deletions of the sFRQ form covering the entire sFRQ ORF (Garceau et al. 1997; Liu et al. 1997, 2000). Immunoprecipitation assays revealed that deletion of only one domain in the middle of the sFRQ ORF (sFRQ6, deletion of FRQ residues 695-781), but not other regions, eliminated the interaction between FRQ and FRH (Fig. 7A; data not shown). These data suggest that this domain is necessary for the interaction of FRQ with FRH. In addition, the level of sFRQ6 is significantly lower than the wild-type sFRQ, consistent with FRH being important in maintaining the steady-state level of FRQ.

To test whether this domain of FRQ is sufficient for the FRQ-FRH interaction, a Neurospora strain (tFRQ) was created in which a truncated FRQ form (residues 656-910, tagged by c-Myc epitope) containing the do- 
main deleted in sFRQ6 is expressed under the control of the qa-2 promoter at the his-3 locus (He et al. 2003). As shown in Figure 7B, this truncated FRQ could form a complex with FRH. Thus, this region of FRQ is necessary and sufficient for the interaction between FRQ and FRH.

If FRH mediates the FRQ-WC interaction, this interaction should be abolished in the sFRQ6 mutant since its FRQ-FRH interaction is abolished. As expected, no FRQ-WC interaction was observed in this mutant (Fig. 7C). Furthermore, the conidiation rhythm of this mutant is very similar to that of frq null strains (data not shown), indicating an essential role for this domain of FRQ in FRQ functions. The ability of FRH to interact with the WC complex independent of FRQ and the requirement of the FRQ-FRH interaction for the FRQ-WC interaction are consistent with a model that FRH helps to recruit FRQ to WC complex to close the circadian negative-feedback loop (Fig. 7D). Thus, FRH is a critical component in the Neurospora circadian negative-feedback loop.

\section{Discussion}

In this study, we identified FRH, an essential RNA helicase that forms a complex with FRQ, as a new core circadian clock component in Neurospora. To understand the role of FRH, we developed an approach to knock down frh expression by inducibly expressing frhspecific dsRNA. Based on the data presented above, FRH appears to have at least two roles in the clock. First, the formation of the FRQ-FRH complexes is important for maintaining the steady-state level of FRQ, since all FRQ forms a complex with FRH and down-regulation of FRH led to low FRQ levels. A similar situation was also observed with WC-1 and WC-2, as low levels of WC-1 were found in the wc-2 null mutant (Cheng et al. 2002). Second, FRH mediates the interaction between FRQ and the WC complex to close the negative-feedback loop. FRH is present in the FRQ-WC complex and the interaction between FRH and WC is independent of FRQ. In addition, deletion of a domain of FRQ that disrupts the FRQ-FRH interaction eliminated the FRQ-WC interaction, suggesting that the FRQ-FRH interaction is important for the FRQ-WC interaction. Furthermore, the down-regulation of FRH led to high levels of frq RNA, an indication that the negative-feedback loop is dysfunctional. However, we could not rule out the possibility that the function of FRH in regulating RNA metabolism may also partly contribute to the changes of frq expression when FRH is down-regulated.

Previously, in vitro gel-shift experiments showed that the WC complex binds to the frq promoter, and this binding was reduced when the in vitro-expressed FRQ was added (Froehlich et al. 2003). Thus, it is possible that FRQ may also be able to interact with the WC complex in the absence of FRH in the cell. Because down-regulation of FRH leads to a low level of FRQ and residual FRH expression, we were not able to examine this possibility in vivo. Although it is unclear which protein, FRQ or $\mathrm{FRH}$, plays the principal role in transcription repression, the current results are consistent with a model that the FRQ-FRH complex functions as the negative element in the Neurospora circadian negative-feedback loop.

RNA helicases are known to unwind RNA and regulate RNA metabolism. Our results presented here reveal a surprising role of an RNA helicase in regulating gene transcription. Most of the FRQ-FRH complexes are in the cytoplasm and are not associated with the WC complex. What are their functions? Since the levels of FRQ are rhythmic in a circadian fashion in the cell and all FRQ proteins are associated with FRH, the amount of FRQ-FRH complex should oscillate daily. The FRH homolog in yeast, Doblp/Mtr4p, has been shown to bind RNA and function as an essential cofactor for the exosome, an important regulator of RNA (rRNA and mRNA) metabolism (Liang et al. 1996; de la Cruz et al. 1998; Jacobs et al. 1998; Allmang et al. 1999; Mitchell and Tollervey 2000; Torchet et al. 2002; Hilleren and Parker 2003). Although the role of FRH as an RNA helicase in the circadian regulation is unclear at the moment, it is likely that the daily fluctuation of the FRQFRH complex may provide a mechanism for the circadian clock to directly control RNA processing and degradation in Neurospora. It is possible that the FRQFRH complex can bind RNA and regulate circadian rhythms in this organism.

\section{Materials and methods}

\section{Strains and growth conditions}

The $b d, a$ strain was used as the wild-type strain in this study. The $f r q^{-}$strain is also designated as $f r q^{10}$ (Aronson et al. 1994b). The 301-6 (bd, his-3, $A)$, 303-10 (bd, frq ${ }^{10}$, his-3, $\left.A\right)$, and 94-1 $\left(b d, f r q^{9}\right.$, his-3) strains were the host strains for the his-3 targeting constructs. The sFRQ3 (deletion of FRQ amino acids 328-422) and sFRQ6 (deletion of FRQ amino acids 695-781) strains were created by transforming $f r q^{10}$ strains with sFRQ constructs containing the in-frame deletions (Liu et al. 2000). The $w c$ strains expressing qaFRQ were described previously (Cheng et al. 2002, 2003). To create the tFRQ strain, a construct was made by inserting a PCR fragment containing FRQ amino acids 656-910 into the pqa.5Myc vector (He et al. 2003), and it was transformed into the his-3 locus of the 301-6 strain. Liquid culture conditions were the same as described previously unless otherwise noted (Aronson et al. 1994a). For liquid cultures containing QA, 0.01 M QA (pH 5.8) were added into liquid culture medium containing $1 \times$ Vogel's, $0.1 \%$ glucose, and $0.17 \%$ arginine (Cheng et al. 2001b). For race tubes containing various concentrations of QA, no glucose was added into the medium.

\section{Creation of the dsfrh strain}

The dsfrh strain was made by introducing a construct expressing a frh-specific RNA hairpin under the control of the $q a-2$ promoter into a wild-type strain. The construct plasmid (pdsfrh) was constructed by inserting an inverted repeat corresponding to the frh gene under the control of the $q a-2$ promoter. Two frh PCR fragments sharing $~ 500-b p$ overlap were generated covering FRH amino acids 696-901 (primers FRH.forHindIIIa and FRH.revEcoRI) and amino acids 730-901 (primers FRH.forHindIIIb and FRH.revSmaI), respectively. The longer fragment contains 
100-bp unique sequence that functions as the loop in the hairpin. These primers contain unique restriction enzyme sites and the primer sequences are FRH.forHindIIIa: 5'-CCCAAGCTTTG TCATTCAGCACCCCCAAAAC-3'; FRH.revEcoRI: 5'-CCGGA ATTCGGCCTTCTTCTTTTCCTTGATC-3'; FRH.forHindIIIb: 5'-CCCAAGCTTCAAACACATCCAGCGACAAACC-3'; and FRH.revSmaI: 5'-TCGTTGATGAAGCCCAGTCTGC-3'. The larger fragment was digested with HindIII and EcoRI while the shorter one was digested with HindIII and SmaI. Afterward, threeway ligation was performed by mixing these two digested PCR products with the EcoRI/SmaI digested vector pDE3dBH.qa (Cheng et al. 2001b). The resulting plasmid pdsfrh that contains the inverted repeat was targeted to the his-3 locus by transformation into 301-6 (bd, his-3, A) and 94-1 (bd, fr $q^{9}$, his-3) strains.

During the review process of this article, a similar method for silencing gene expression in Neurospora was reported (Goldoni et al. 2004).

\section{Purification of the FRQ-FRH complex from Neurospora}

All purification procedures were carried out at $4^{\circ} \mathrm{C}$. Twelve grams of Neurospora tissue from the $f r q^{-}$, MycFRQ strain or the wild-type strain grown in LL were harvested. Whole-cell lysate $(\sim 200 \mathrm{mg})$ in lysis buffer (20 mM Tris.Cl at pH 7.4, $50 \mathrm{mM} \mathrm{NaCl}$, and $10 \%$ glycerol plus protease inhibitors) was applied to a Hitrap-Q Sepharose column (5 mL bed volume) (Amersham Pharmacia Biotech) that has been equilibrated with buffer A $(20 \mathrm{mM}$ Tris. $\mathrm{Cl}$ at $\mathrm{pH} 7.4,50 \mathrm{mM} \mathrm{NaCl}$ ). After washing with buffer A, the bound materials on the column were eluted with $50 \mathrm{~mL}$ linear gradient from $50 \mathrm{mM} \mathrm{NaCl}$ to $650 \mathrm{mM} \mathrm{NaCl}$ in buffer A. After Western blot analysis, fractions containing FRQ ( 450 $\mathrm{mM} \mathrm{NaCl}$ ) were pooled together and concentrated to $1 \mathrm{~mL}$ using Centricon YM-30 (Millipore). Immunoprecipitation was performed by adding $15 \mu \mathrm{L}$ c-Myc monoclonal antibody-coupled agarose beads (9E10AC, Santa Cruz Biotechnology). After incubation at $4^{\circ} \mathrm{C}$ with gentle rotation for $3 \mathrm{~h}$, the beads were washed with $20 \mathrm{mM}$ Tris. $\mathrm{Cl}$ (pH 7.4), $50 \mathrm{mM} \mathrm{NaCl}$, and $20 \mathrm{mM}$ Tris. $\mathrm{Cl}$ (pH 7.4), $500 \mathrm{mM} \mathrm{NaCl}$ three times alternately before being washed with water once. The beads were boiled for $3 \mathrm{~min}$ in $30 \mu \mathrm{L} 1 \times$ SDS loading buffer and analyzed by SDS PAGE $(4 \% \sim 20 \%)$. The gel was subsequently silver stained according to the manufacturer's instructions (SiverQuest, Invitrogen). The specific bands were excised and subjected to tryptic digestion and Nano-HPLC/electrospray mass spectrometry analysis (University of Texas Southwestern Protein Chemistry Core facility). The resulting MS files were searched against NCBI-nr protein sequence databases for protein identification.

\section{Generation of antiserum against FRH}

GST-FRH (containing FRH amino acids 1-374) fusion protein was expressed in BL21 cells and the inclusion bodies containing the recombinant protein were purified and used as the antigen to generate rabbit polyclonal antiserum as described previously (Cheng et al. 2001a).

\section{Immunodepletion}

The preimmune serum, FRQ or FRH antiserum $(100 \mu \mathrm{L})$ was first coupled to $50 \mu \mathrm{L}$ of protein $\mathrm{G}$ beads overnight at $4^{\circ} \mathrm{C}$ in the presence of $10 \mathrm{mg} / \mathrm{mL}$ BSA and $0.1 \%$ NP-40 in $1 \mathrm{~mL}$ lysis buffer (50 mM HEPES at pH 7.4, $137 \mathrm{mM} \mathrm{NaCl}$, and $10 \%$ glycerol). The protein G-coupled IgGs $(20 \mu \mathrm{L}$, packed volume) were washed with lysis buffer four times and then incubated with 1 mg whole-cell lysates in the lysis buffer containing $0.05 \%$ NP-
40 overnight at $4^{\circ} \mathrm{C}$. After centrifugation, supernatants were resolved by SDS-PAGE and analyzed by Western blot analysis.

\section{Protein and RNA analyses}

Protein extraction, quantification, Western blot analysis, and immunoprecipitation assays were performed as previously described (Garceau et al. 1997; Cheng et al. 2001a). Equal amounts of total protein $(40 \mu \mathrm{g})$ were loaded in each protein lane, and after electrophoresis, proteins were transferred onto PVDF membrane and Western blot analysis was performed. Nuclear and cytoplasmic protein extracts were prepared as previously described (Luo et al. 1998) and equal amounts (5 $\mu$ g) of nuclear and cytoplasmic proteins were loaded in SDS-PAGE.

RNA extraction and Northern blot analyses were performed as described previously (Aronson et al. 1994a). Equal amounts of total RNA $(20 \mu \mathrm{g})$ were loaded onto agarose gels for electrophoresis, and the gels were blotted and probed with an RNA probe specific for $f r q$, frh, or $c c g-2$.

\section{Acknowledgments}

We thank Drs. Hongtao Yu and James Stull for critical reading of the manuscript. We thank Yue Chen from the Southwestern Protein Chemistry Core facility for protein identification. This research was supported by grants from the National Institutes of Health (GM062591 and GM068496) and the Welch Foundation to Y.L. Y.L. is the Louise W. Kahn endowed scholar in Biomedical Research at the University of Texas Southwestern Medical Center.

\section{References}

Allmang, C., Kufel, J., Chanfreau, G., Mitchell, P., Petfalski, E., and Tollervey, D. 1999. Functions of the exosome in rRNA, snoRNA and snRNA synthesis. EMBO J. 18: 5399-5410.

Aronson, B., Johnson, K., Loros, J.J., and Dunlap, J.C. 1994a. Negative feedback defining a circadian clock: Autoregulation in the clock gene frequency. Science 263: 1578-1584.

Aronson, B.D., Johnson, K.A., and Dunlap, J.C. 1994b. The circadian clock locus frequency: A single ORF defines period length and temperature compensation. Proc. Natl. Acad. Sci. 91: 7683-7687.

Bell-Pedersen, D., Dunlap, J.C., and Loros, J.J. 1992. The Neurospora circadian clock-controlled gene, $c c g-2$, is allelic to eas and encodes a fungal hydrophobin required for formation of the conidial rodlet layer. Genes \& Dev. 6: 2382-2394.

Cheng, P., Yang, Y., Heintzen, C., and Liu, Y. 2001a. Coiled-coil domain mediated FRQ-FRQ interaction is essential for its circadian clock function in Neurospora. EMBO J. 20: 101108.

Cheng, P., Yang, Y., and Liu, Y. 2001b. Interlocked feedback loops contribute to the robustness of the Neurospora circadian clock. Proc. Natl. Acad. Sci. 98: 7408-7413.

Cheng, P., Yang, Y., Gardner, K.H., and Liu, Y. 2002. PAS domain-mediated WC-1/WC-2 interaction is essential for maintaining the steady state level of WC-1 and the function of both proteins in circadian clock and light responses of Neurospora. Mol. Cell. Biol. 22: 517-524.

Cheng, P., Yang, Y., Wang, L., He, Q., and Liu, Y. 2003. WHITE COLLAR-1, a multifunctional Neurospora protein involved in the circadian feedback loops, light sensing, and transcription repression of wc-2. J. Biol. Chem. 278: 3801-3808.

Crosthwaite, S.K., Dunlap, J.C., and Loros, J.J. 1997. Neurospora $w c-1$ and $w c-2$ : Transcription, photoresponses, and the ori- 
gins of circadian rhythmicity. Science 276: 763-769.

de la Cruz, J., Kressler, D., Tollervey, D., and Linder, P. 1998. Doblp (Mtr4p) is a putative ATP-dependent RNA helicase required for the $3^{\prime}$ end formation of 5.8S rRNA in Saccharomyces cerevisiae. EMBO J. 17: 1128-1140.

Denault, D.L., Loros, J.J., and Dunlap, J.C. 2001. WC-2 mediates WC-1-FRQ interaction within the PAS protein-linked circadian feedback loop of Neurospora. EMBO J. 20: 109-117.

Dunlap, J.C. 1999. Molecular bases for circadian clocks. Cell 96: $271-290$.

Froehlich, A.C., Loros, J.J., and Dunlap, J.C. 2003. Rhythmic binding of a WHITE COLLAR-containing complex to the frequency promoter is inhibited by FREQUENCY. Proc. Natl. Acad. Sci. 100: 5914-5919.

Garceau, N., Liu, Y., Loros, J.J., and Dunlap, J.C. 1997. Alternative initiation of translation and time-specific phosphorylation yield multiple forms of the essential clock protein FREQUENCY. Cell 89: 469-476.

Giles, N.H., Case, M.E., Baum, J., Geever, R., Huiet, L., Patel, V., and Tyler, B. 1985. Gene organization and regulation in the qa (quinic acid) gene cluster of Neurospora crassa. Microbio. Rev. 49: 338-358.

Goldoni, M., Azzalin, G., Macino, G., and Cogoni, C. 2004. Efficient gene silencing by expression of double stranded RNA in Neurospora crassa. Fungal Genet. Biol. 41: 10161024.

Gorl, M., Merrow, M., Huttner, B., Johnson, J., Roenneberg, T., and Brunner, M. 2001. A PEST-like element in FREQUENCY determines the length of the circadian period in Neurospora crassa. EMBO J. 20: 7074-7084.

He, Q., Cheng, P., Yang, Y., Wang, L., Gardner, K.H., and Liu, Y. 2002. White collar-1, a DNA binding transcription factor and a light sensor. Science 297: 840-843.

He, Q., Cheng, P., Yang, Y., He, Q., Yu, H., and Liu, Y. 2003. FWD1-mediated degradation of FREQUENCY in Neurospora establishes a conserved mechanism for circadian clock regulation. $E M B O$ J. 22: 4421-4430.

Hilleren, P.J. and Parker, R. 2003. Cytoplasmic degradation of splice-defective pre-mRNAs and intermediates. Mol. Cell 12: $1453-1465$.

Jacobs, J.S., Anderson, A.R., and Parker, R.P. 1998. The 3' to 5' degradation of yeast mRNAs is a general mechanism for mRNA turnover that requires the SKI2 DEVH box protein and $3^{\prime}$ to $5^{\prime}$ exonucleases of the exosome complex. EMBO $J$. 17: 1497-1506.

Kalidas, S. and Smith, D.P. 2002. Novel genomic cDNA hybrids produce effective RNA interference in adult Drosophila. Neuron 33: 177-184.

King, D.P. and Takahashi, J.S. 2000. Molecular genetics of circadian rhythms in mammals. Annu. Rev. Neurosci. 23: 713742.

Lee, K., Loros, J.J., and Dunlap, J.C. 2000. Interconnected feedback loops in the Neurospora circadian system. Science 289: $107-110$.

Liang, S., Hitomi, M., Hu, Y.H., Liu, Y., and Tartakoff, A.M. 1996. A DEAD-box-family protein is required for nucleocytoplasmic transport of yeast mRNA. Mol. Cell. Biol. 16: 5139-5146.

Liu, Y., Garceau, N., Loros, J.J., and Dunlap, J.C. 1997. Thermally regulated translational control mediates an aspect of temperature compensation in the Neurospora circadian clock. Cell 89: 477-486.

Liu, Y., Loros, J., and Dunlap, J.C. 2000. Phosphorylation of the Neurospora clock protein FREQUENCY determines its degradation rate and strongly influences the period length of the circadian clock. Proc. Nat1. Acad. Sci. 97: 234-239.
Loros, J.J. and Dunlap, J.C. 2001. Genetic and molecular analysis of circadian rhythms in NEUROSPORA. Annu. Rev. Physiol. 63: 757-794.

Luo, C., Loros, J.J., and Dunlap, J.C. 1998. Nuclear localization is required for function of the essential clock protein FREQUENCY. EMBO I. 17: 1228-1235.

Merrow, M., Garceau, N., and Dunlap, J.C. 1997. Dissection of a circadian oscillation into discrete domains. Proc. Natl. Acad. Sci. 94: 3877-3882.

Merrow, M., Franchi, L., Dragovic, Z., Gorl, M., Johnson, J., Brunner, M., Macino, G., and Roenneberg, T. 2001. Circadian regulation of the light input pathway in Neurospora crassa. EMBO J. 20: 307-315.

Mitchell, P. and Tollervey, D. 2000. Musing on the structural organization of the exosome complex. Nat. Struct. Biol. 7: 843-846.

Reppert, S.M. and Weaver, D.R. 2001. Molecular analysis of mammalian circadian rhythms. Annu. Rev. Physiol. 63: 647-676.

Rocak, S. and Linder, P. 2004. DEAD-box proteins: The driving forces behind RNA metabolism. Nat. Rev. Mol. Cell Biol. 5: 232-241.

Schwerdtfeger, C. and Linden, H. 2000. Localization and lightdependent phosphorylation of white collar 1 and 2, the two central components of blue light signaling in Neurospora crassa. Eur. J. Biochem. 267: 414-422.

Torchet, C., Bousquet-Antonelli, C., Milligan, L., Thompson, E., Kufel, J., and Tollervey, D. 2002. Processing of 3'-extended read-through transcripts by the exosome can generate functional mRNAs. Mol. Cell 9: 1285-1296.

Yang, Y., Cheng, P., and Liu, Y. 2002. Regulation of the Neurospora circadian clock by casein kinase II. Genes \& Dev. 16: $994-1006$.

Young, M.W. and Kay, S.A. 2001. Time zones: A comparative genetics of circadian clocks. Nat. Rev. Genet. 2: 702-715. 


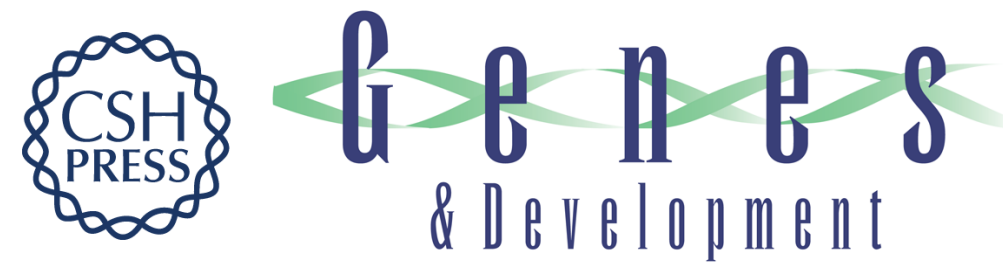

\section{Regulation of the Neurospora circadian clock by an RNA helicase}

Ping Cheng, Qun He, Qiyang He, et al.

Genes Dev. 2005, 19:

Access the most recent version at doi:10.1101/gad.1266805

References This article cites 38 articles, 23 of which can be accessed free at: http://genesdev.cshlp.org/content/19/2/234.full.html\#ref-list-1

License

Email Alerting Receive free email alerts when new articles cite this article - sign up in the box at the top Service right corner of the article or click here.

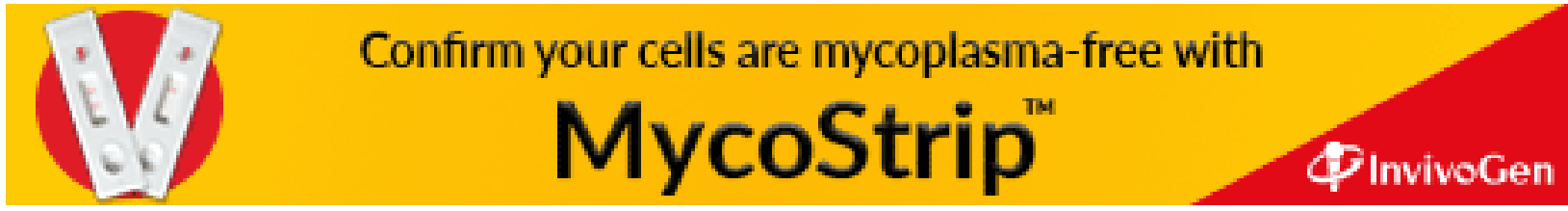

